\title{
Perfusion Enhances Hypertrophic Chondrocyte Matrix Deposition, But Not the Bone Formation
}

\author{
Jonathan C. Bernhard, PhD, Elizabeth Hulphers, MS,, Bernhard Rieder, MS, James Ferguson, DVM, ${ }^{3}$ \\ Dominik Rünzler, $\mathrm{PhD}^{2}$, Thomas Nau, MD, Heinz Redl, $\mathrm{PhD}^{3}$, and Gordana Vunjak-Novakovic, $\mathrm{PhD}^{1,4}$
}

Perfusion bioreactors have been an effective tool in bone tissue engineering. Improved nutrient delivery and the application of shear forces have stimulated osteoblast differentiation and matrix production, allowing for generation of large, clinically sized constructs. Differentiation of hypertrophic chondrocytes has been considered an alternative strategy for bone tissue engineering. We studied the effects of perfusion on hypertrophic chondrocyte differentiation, matrix production, and subsequent bone formation. Hypertrophic constructs were created by differentiation in chondrogenic medium ( 2 weeks) and maturation in hypertrophic medium (3 weeks). Bioreactors were customized to study a range of flow rates $(0-1200 \mu \mathrm{m} / \mathrm{s})$. During chondrogenic differentiation, increased flow rates correlated with cartilage matrix deposition and the presence of collagen type X. During induced hypertrophic maturation, increased flow rates correlated with bone template deposition and the increased secretion of chondroprotective cytokines. Following an 8-week implantation into the criticalsize femoral defect in nude rats, nonperfused constructs displayed larger bone volume, more compact mineralized matrix, and better integration with the adjacent native bone. Therefore, although medium perfusion stimulated the formation of bone template in vitro, it failed to enhance bone regeneration in vivo. However, the promising results of the less developed template in the critical-sized defect warrant further investigation, beyond interstitial flow, into the specific environment needed to optimize hypertrophic chondrocyte-based constructs for bone repair.

Keywords: perfusion flow, bioreactors, hypertrophic chondrocytes, bone tissue engineering

\section{Introduction}

B IOMIMETIC APPROACHES RECAPITULATING some of the natural mechanisms of tissue formation ${ }^{1}$ have gained increasing interest in engineering of functional bone grafts. One of the most promising directions is the study of endochondral ossification strategies in complex bone repair environments. In particular, utilization of cartilage anlage has resulted in the ability to form bone in vivo. ${ }^{2-7}$ Among these strategies, the use of hypertrophic chondrocytes, the cell that orchestrates endochondral ossification, appears particularly promising as the maturation from chondrocytes to hypertrophic chondrocytes resulted in significantly more bone formation. ${ }^{8}$ The hypertrophic chondrocyte constructs have shown an ability to create maturing bone in vitro, which subsequently developed vasculature and bone marrow following subcutaneous implantation, 6,9 and facilitated healing of calvarial $^{10,11}$ and long bone ${ }^{12}$ defects. Robust performance of these constructs and their superiority over traditionally utilized osteoblast constructs ${ }^{11,12}$ suggested clinical potential for healing complex bone fractures.

Bioreactors provide an essential tool for the creation of tissue constructs, allowing control of numerous environmental factors that influence construct composition and behavior. ${ }^{13,14}$ In osteochondral tissue engineering, perfusion bioreactors have been applied to both osteoblasts and chondrocytes. Perfusion bioreactors increased nutrient delivery ${ }^{15,16}$ and provided shear stress $^{16,17}$ that increased osteoblast cellularity, activity, matrix production, and in vivo bone regeneration, ${ }^{18-23}$ as well as chondrocyte differentiation and cartilage matrix production. ${ }^{24-26}$

\footnotetext{
${ }^{1}$ Department of Biomedical Engineering, Columbia University, New York, New York.

${ }^{2}$ Department of Biochemical Engineering, University of Applied Sciences Technikum Wien, Austrian Cluster for Tissue Regeneration Vienna, Vienna, Austria.

${ }^{3}$ Ludwig Boltzmann Institute of Experimental and Clinical Traumatology, University of Vienna, Austrian Cluster for Tissue Regeneration, Vienna, Austria.

${ }^{4}$ Department of Medicine, Columbia University, New York, New York.
} 
Through the application of perfusion flow, large, autologous, anatomically exact bone grafts were created, which successfully repaired craniofacial defects. ${ }^{23}$ The goal of our study was to investigate the effect of perfusion flow on hypertrophic chondrocyte-based bone constructs.

Although hypertrophic chondrocytes in perfusion bioreactors have not been directly studied, a recent study showed that chondrogenic culture of stem cell pellets in a perfusion bioreactor increased expression of hypertrophic markers, although without effects on cartilaginous matrix production. ${ }^{27}$ Dynamic culture stimulated hypertrophic chondrocyte differentiation and resulted in increased bone production. ${ }^{28,29}$ We hypothesized that the perfusion flow will facilitate hypertrophic chondrocyte differentiation, deposition, and bone formation.

To test this hypothesis, we created hypertrophic chondrocytebased constructs with clinical applicability in mind. Human bone marrow-derived stem cells (BMSCs), selected because of their extensive use in tissue engineering of bone and cartilage, were seeded into decellularized trabecular bone scaffolds, selected because of their osteogenic nature and mechanical properties, and cultured for 5 weeks. Perfusion flow was set to 4 different levels: 0 (static control), 100, 400, and $1200 \mu \mathrm{m} / \mathrm{s}$, based on providing a broad range of flow rates to discern the impact of perfusion flow, while also providing similar rates to our previous, impactful work with osteoblasts. ${ }^{30}$ Tissue samples were harvested after chondrogenic differentiation at 2 weeks and after construct cultivation at 5 weeks, and evaluated for hypertrophic chondrocyte differentiation and bone matrix deposition. At the end of in vitro culture, tissue constructs grown without perfusion and at the perfusion rate of $400 \mu \mathrm{m} / \mathrm{s}$ were implanted into an orthotopic, critical-sized femoral defect in athymic rats, and the bone regeneration was studied over an additional 8 weeks following implantation.

\section{Materials and Methods}

All materials were purchased from Sigma-Aldrich (St. Louis, MO) unless otherwise noted.

\section{Scaffold preparation}

Trabecular bone cores were harvested from juvenile bovine wrists as in previous studies. ${ }^{12,22}$ Briefly, wrist joints were obtained from a local butcher and the metacarpal bone was isolated and cleaned from all other tissue. Diamond tip bores (Starlite Industries, Rosemont, PA), $4 \mathrm{~mm}$ in diameter, were utilized to remove trabecular bone. Scaffolds were trimmed to $5 \mathrm{~mm}$ height by $4 \mathrm{~mm}$ diameter. Trimmed cores were then washed of marrow and tissue by utilizing a highpowered water jet. Scaffolds were decellularized following our published protocols. ${ }^{22}$ Briefly, scaffolds were washed in a series of solutions: (1) $0.1 \%$ ethylenediaminetetraacetic acid (EDTA) in phosphate-buffered saline (PBS) for $1 \mathrm{~h},(2)$ hypotonic buffer consisting of $10 \mathrm{mM}$ Tris and $0.1 \%$ EDTA in PBS for $12 \mathrm{~h}$ at $4^{\circ} \mathrm{C}$, (3) detergent consisting of $10 \mathrm{mM}$ Tris and $0.5 \%$ sodium dodecyl sulfate in PBS for $24 \mathrm{~h}$ at room temperature on an orbital shaker at 300 revolutions/ min, and (4) enzymatic solution of $100 \mathrm{U} / \mathrm{mL}$ DNase and $1 \mathrm{U} / \mathrm{mL}$ of RNase with $10 \mathrm{mM}$ Tris in PBS for $6 \mathrm{~h}$ at $37^{\circ} \mathrm{C}$. After multiple washes in PBS, scaffolds were frozen and lyophilized. In an attempt to manage core variability, scaffolds were sorted based on their bulk density (mass/ volume), with densities used for this study within the range of -0.35 to $0.50 \mathrm{~g} / \mathrm{mL}$. Scaffolds were disinfected by incubating in $70 \%$ ethanol for 2 days under ultraviolet light before cell seeding.

\section{Cell expansion and seeding}

Human BMSCs were obtained from Lonza (Basel, CH) and expanded until passage 5 in an expansion medium consisting of high glucose medium with L-glutamine, $10 \%$ fetal bovine serum, $1 \%$ penicillin/streptomycin $(\mathrm{P} / \mathrm{S})$, and $1 \mathrm{ng} / \mathrm{mL}$ basic fibroblast growth factor. Before seeding, scaffolds were rinsed of $70 \%$ ethanol with sterile PBS, and incubated for 1 day in the expansion medium. After passage 5, BMSCs were trypsinized, resuspended in a culture medium at a concentration of 30 million cells $/ \mathrm{mL}$, and integrated into the demineralized cancelous bone (DCB) scaffolds. As the scaffolds had an estimated volume of $75 \mu \mathrm{L}, 2.25$ million cells were seeded per scaffold.

\section{Perfusion bioreactors and hypertrophic differentiation}

The perfusion bioreactor utilized in the experiments had previously been developed and characterized for bone tissue engineering with osteoblasts. ${ }^{21,31}$ The bioreactor utilizes a central input that evenly divides the flow of medium into six individual culture wells. Polydimethylsiloxane rings were used to seal scaffolds in the culture wells, and to route perfusion flow into and through the scaffold. Upon passage through the scaffolds, the medium was collected in a reservoir above the constructs, where it was continuously equilibrated with oxygen and $\mathrm{pH}$ before recirculating through the exit port back into the wells. The bioreactor was powered by a multichannel peristaltic pump (Cole-Parmer, Vernon Hills, IL). Each six-well bioreactor was set to a specific flow rate, by adjusting the diameter of the tubing (Cole-Parmer). It was determined that pump diameters of $0.51,0.89$, and 2.29 millimeters corresponded to flow rates of 136,413 , and $1144 \mu \mathrm{m} / \mathrm{s}$, respectively, at a pump rate of 225 revolutions/min (Fig. 1). Based on the analysis completed previously, ${ }^{30}$ these rates corresponded to shear stresses ranging from 1 to $15 \mathrm{MPa}$, with 100 and $1200 \mu \mathrm{m} / \mathrm{s}$ providing an order of magnitude difference in both flow rate and shear stress, and the $400 \mu \mathrm{m} / \mathrm{s}$ matching the optimal flow rate and shear stress for osteoblast cultivation. For simplicity, the groups corresponding to these flow rates were labeled 100, 400, and $1200 \mu \mathrm{m} / \mathrm{s}$.

Seeded constructs were then placed within the bioreactor wells and perfusion flow was started. All experimental groups $(0,100,400$, and $1200 \mu \mathrm{m} / \mathrm{s})$ were cultured under the same 5-week long differentiation regime (Fig. 1). For the first 2 weeks, the constructs were cultured in a chondrogenic medium consisting of high glucose DMEM (ThermoFisher, Waltham, MA), $100 \mathrm{nM}$ dexamethasone, $50 \mu \mathrm{g} / \mathrm{mL}$ ascorbic acid, $50 \mu \mathrm{g} / \mathrm{mL}$ proline, $100 \mu \mathrm{g} / \mathrm{mL}$ sodium pyruvate, $1 \%$ $\mathrm{ITS}^{+}, 1 \% \mathrm{P} / \mathrm{S}$, and $10 \mathrm{ng} / \mathrm{mL}$ transforming growth factor- $\beta 3$ (TGF- $\beta 3$ ). The constructs were then matured to hypertrophic chondrocytes over the next 3 weeks in a hypertrophic medium, consisting of high glucose DMEM (ThermoFisher) supplemented with $1 \mathrm{nM}$ dexamethasone, $50 \mu \mathrm{g} / \mathrm{mL}$ ascorbic acid, $50 \mu \mathrm{g} / \mathrm{mL}$ proline, $100 \mu \mathrm{g} / \mathrm{mL}$ sodium pyruvate, $1 \% \mathrm{ITS}^{+}, 1 \% \mathrm{P} / \mathrm{S}, 50 \mathrm{ng} / \mathrm{mL}$ L-thyroxine, and $5 \mathrm{mM}$ of 
$\beta$-glycerophosphate. Constructs were harvested at 2 weeks, at the end of chondrogenic culture, and after 5 weeks, at the end of in vitro culture.

\section{Biochemical assays}

Constructs from both harvest time points $(n=4)$ were weighed and digested with papain $(40 \mathrm{U} / \mathrm{mg})$ in digest buffer $(0.1 \mathrm{M}$ sodium acetate, $10 \mathrm{mM}$ cysteine $\mathrm{HCl}$, and $50 \mathrm{mM}$ EDTA, pH 6.0) at $60^{\circ} \mathrm{C}$ overnight. DNA content was measured by the Quant-IT PicoGreen assay kit (ThermoFisher) and normalized to the wet weight. The manufacturer's instructions were followed, and the supplied lambda DNA was used as the standard.

Sulfated glycosaminoglycan (GAG) content was measured from the papain digested constructs using the dimethylmethylene blue dye assay, normalized to wet weight, with chondroitin 6 sulfate utilized as control. The GAG content was normalized to the construct DNA.

\section{Real-time polymerase chain reaction}

RNA was extracted from the constructs using TRIzol (ThermoFisher). RNA content was measured using NanoDrop spectrophotometric quantitation (ThermoFisher) and contaminating DNA was removed through DNAase I treatment. cDNA was transcribed from the RNA through the use of the High-Capacity cDNA Reverse Transcription kit (ThermoFisher) according to the manufacturer's instructions. Quantitative reverse transcriptase (RT) polymerase chain reaction (PCR) was performed using Fast Sybr Green master mix (ThermoFisher) with gene expression normalized using the $\Delta \mathrm{C}_{\mathrm{t}}$, the $\mathrm{C}_{\mathrm{t}}$ of GAPDH subtracted from the $\mathrm{C}_{\mathrm{t}}$ of the gene of interest. Samples were run in technical duplicates, with $n=4$ biological replicates for each experimental group. The genes examined were GAPDH (F: $A A G G$ TGAAGGTCGGAGTCAAC, R: GGGGTCATTGATGGCAA $C A A T A)$, collagen type 10 (COL10A1, F: CATAAAAGG CССАCTACCCAAC, R: ACCTTGCTCTCCTCTTACTGC), RUNX2 (F: CCGTCTTCACAAATCCTCCCC, R: CCCGAG GTCCATCTACTGTAAC), bone sialoprotein (IBSP, F: GAA CCTCGTGGGGACAATTAC, R: CATCATAGCCATCGTAG $C C T T G$ ), and alkaline phosphatase (ALPL, F: GGGACTGG TACTCAGACAACG, R: GTAGGCGATGTCCTTACAGCC).

\section{Analysis of secreted cytokines}

The conditioned medium (collected over 4 days of culture) was collected from each bioreactor. Commercially available quantitative ELISA kits were purchased for the following cytokines: VEGF-A (RayBiotech, Norcross, GA), BMP2 (RayBiotech), BMP7 (RayBiotech), beta-catenin (LifeSpan BioSciences, Seattle, WA), DKK1 (RayBiotech), and IHH (LifeSpan BioSciences). Assays were performed according to the manufacturer's instructions, with the conditioned medium incubated overnight at $4^{\circ} \mathrm{C}$. Conditioned medium samples were pooled together for each experimental group and tested in triplicate.

\section{Defect creation and graft implantation}

Animal studies were conducted under an approved protocol and with the permit of the municipal government of Vienna, Austria. The experiments were consistent with the
Guide for the Care and Use of Laboratory Animals of the National Institute of Health (revised 2011). Male Rowett Nude (RNU) rats, weighing $250 \mathrm{~g}$ at the time of surgery, were kept in housing cages with filter tops, in groups of two. Preoperatively, the animals were administered subcutaneously $0.05 \mathrm{mg} / \mathrm{kg}$ buprenorphine (Bupaq; Richterpharma AG, Austria) and $4 \mathrm{mg} / \mathrm{kg}$ carprofen (Rimadyl; Zoetis Osterreich Gesm.b.H, Austria). Anesthesia was induced with isoflurane (Forane; AbbVie Gesm.b.H, Austria) and maintained with $1.5-2.5 \%$ isoflurane/oxygen by way of nosecone inhalation.

Once the animal was under stable anesthesia, a lateral approach was used to expose the right femur. After fixation with a four-pin POM fixator (modified from the method described in Betz et $a l^{32}$ ), a defect of $5 \mathrm{~mm}$ was created with a Gigli wire saw. Grafts were trimmed to fit, placed into the defect, and the muscle and skin were sutured around the graft and the fixator, respectively. For the two experimental groups (nonperfusion control; perfusion at $400 \mu \mathrm{m} / \mathrm{s}$ ), four rats in each group underwent implantation, with an additional two rats not receiving implants to confirm the absence of spontaneous healing in critical-size defects. Pain management was completed with subcutaneous injections of $0.05 \mathrm{mg} / \mathrm{kg}$ buprenorphine and $4 \mathrm{mg} / \mathrm{kg}$ carprofen over the first 4 days postimplantation. The rats with an open defect and no implant demonstrated a non-healing non-union failure before study endpoint, and were euthanized. Eight weeks postimplantation, the rats were euthanized by an overdose injection of intracardially delivered thiopental sodium, while under deep isoflurane anesthesia. The right femur of each animal was harvested for detailed characterization.

\section{Histology and immunohistochemistry}

Preimplantation and postimplantation tissue samples (femurs with the implanted grafts) were preserved in $10 \%$ formalin for $24 \mathrm{~h}$, rinsed excessively in PBS, decalcified using a formic acid-based solution (Immunocal Decalcifier; StatLab, McKinney, TX), and dehydrated in graded ethanol solutions. After dehydration, samples were embedded in paraffin and sectioned at $6 \mu \mathrm{m}$.

Sample $4 \mathrm{~s}$ of preimplantation chondrogenic constructs were stained with Alcian blue for GAG following standard protocols. Immunohistochemistry was performed on sections of chondrogenic construct by first incubating the samples in $0.05 \%$ trypsin at $37^{\circ} \mathrm{C}$ for $15 \mathrm{~min}$. After rinsing in PBS, samples were incubated in $0.3 \%$ hydrogen peroxide in absolute methanol for $30 \mathrm{~min}$ with gentle shaking at room temperature. After washing in PBS, the Vectastain Elite Universal staining kit (Vector Laboratories, Burlingame, CA) was utilized to prepare and detect the primary antibody. The collagen type II antibody was obtained from Abcam (San Francisco, CA) and applied at a dilution of 1/50. Samples were counterstained with Hematoxylin QS (Vector Laboratories).

To demonstrate the progression of hypertrophic chondrocyte maturation, collagen type $\mathrm{X}$ immunohistochemistry was performed on both chondrogenic and hypertrophic samples from each group. Histological sections were first incubated with $2 \mathrm{mg} / \mathrm{mL}$ hyaluronidase (type IV from bovine testes) for $60 \mathrm{~min}$ at $37^{\circ} \mathrm{C}$, followed by PBS washing, and then incubated with $1 \mathrm{mg} / \mathrm{mL}$ Pronase $\mathrm{E}$ treatment for 
$60 \mathrm{~min}$ at $37^{\circ} \mathrm{C}$. After washing in PBS, the Vectastain Elite Universal staining kit (Vector Laboratories) was utilized to prepare and detect the primary antibody. The collagen type $\mathrm{X}$ antibody was obtained from Abcam and applied at a dilution of 1/2000. Samples were counterstained with Hematoxylin QS (Vector Laboratories).

Immunohistochemistry was performed to visualize bone sialoprotein and osteopontin in the constructs. Antigen retrieval was done on histological slides placed in a container filled with citrate buffer and submerged into boiling water for $20 \mathrm{~min}$. Slides were blocked by incubation of samples in $0.3 \%$ hydrogen peroxide for $30 \mathrm{~min}$. The Vectastain Elite Universal staining kit (Vector Laboratories) was utilized to prepare and detect the primary antibody. Primary antibodies for bone sialoprotein (1/500 dilution; EMD Millipore, Bilerica, MA) and osteopontin (1/500 dilution; EMD Millipore) were incubated on the slides overnight at $4^{\circ} \mathrm{C}$. Samples were counterstained with Hematoxylin QS (Vector Laboratories). Preimplantation and postimplantation samples were stained with Movat's Pentachrome (Cancer Diagnostics, Durham, $\mathrm{NC}$ ) according to the manufacturer's instructions.

\section{Microcomputed tomography}

Explants were scanned on a $\mu \mathrm{CT} 50$ (Scanco Medical, Bruttisellen, Switzerland) using scanner settings as follows: voltage $70 \mathrm{kV}$, current $0.200 \mathrm{~mA}$, and slice thickness $10 \mu \mathrm{m}$. Scans had a $10 \mu \mathrm{m}$ isotropic resolution. Three-dimensional (3D) reconstructions and quantitation were performed by a global thresholding technique set at $282.9 \mathrm{mg}$ hydroxyapatite $(\mathrm{HA}) / \mathrm{cm}^{3}$. Bone volume and bone surface/bone volume (BS/BV) were calculated for the scanned samples ( $n=4$ biological replicates) utilizing software provided by Scanco Medical.

\section{Statistics}

All data are presented as mean \pm standard deviation. Statistical significance of biochemical quantitation and real-time PCR data was evaluated using a one-way analysis of variance followed by Tukey's post-test, $\alpha=0.05$, with significance determined by $p<0.05$ using statistical software (Prism Software; GraphPad, La Jolla, CA). Statistical significance of cytokine secretion and microcomputed tomography $(\mu \mathrm{CT})$ bone morphometry was determined using a Student's $t$-test, $\alpha=0.05$, with significance determined by $p<0.05$.

\section{Results}

Perfusion (interstitial flow) at a set flow rate was applied to tissue-engineered constructs to determine its effects on hypertrophic chondrocyte differentiation and matrix production. The effects of three different flow rates (100, 400, and $1200 \mu \mathrm{m} / \mathrm{s})$ were compared to nonperfused $(0 \mu \mathrm{m} / \mathrm{s})$ controls (Fig. 1).

Tissues were harvested after 2 weeks, at the endpoint of chondrogenic differentiation, and evaluated for cartilage matrix production (Fig. 2). The DNA content, normalized to construct wet weight, was not significantly different between the 0,100 , and $400 \mu \mathrm{m} / \mathrm{s}$ constructs, whereas the $1200 \mu \mathrm{m} / \mathrm{s}$ constructs had significantly more DNA compared to all other three groups (Fig. 2A). Similarly, the GAG content was highest in the

\section{Scaffold Seeding and Differentiation}
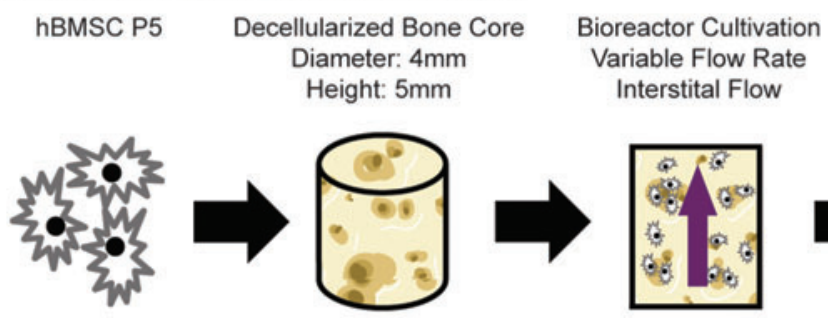

$5 \mathrm{~mm}$ Crticial Size Femoral Defect
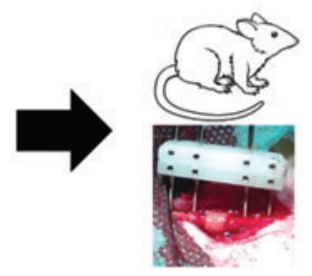

Culture Regime

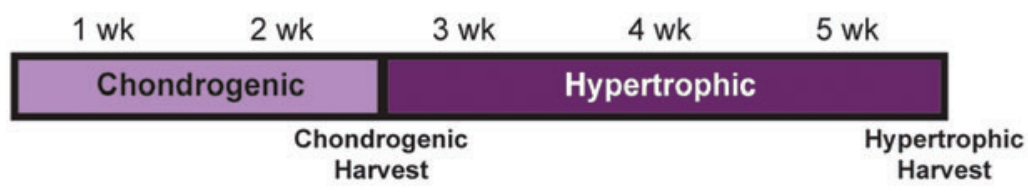

Flow Rate Validation

\begin{tabular}{|r|l|r|r|}
\hline $\begin{array}{l}\text { Group } \\
\text { Name }\end{array}$ & $\begin{array}{l}\text { Tubing } \\
\text { Diameter }(\mathrm{mm})\end{array}$ & $\begin{array}{l}\text { Flow Rate } \\
(\mu \mathrm{m} / \mathrm{s})\end{array}$ & $\begin{array}{l}\text { Standard } \\
\text { Deviation }\end{array}$ \\
\hline 0 & $\mathrm{~N} / \mathrm{A}$ & 0 & $\mathrm{~N} / \mathrm{A}$ \\
\hline 100 & 0.51 & 135.80 & 11.30 \\
\hline 400 & 0.89 & 413.48 & 23.40 \\
\hline 1200 & 2.29 & 1143.72 & 53.09 \\
\hline
\end{tabular}

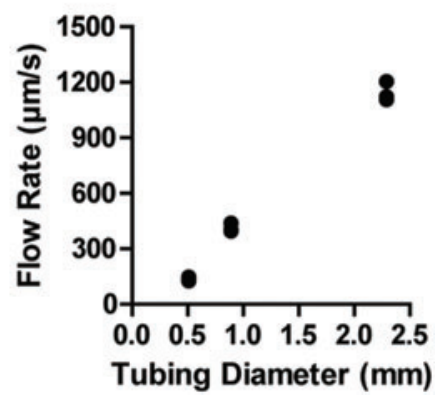

FIG. 1. Creation of hypertrophic chondrocyte constructs through application of variable flow rates. Bone cores were extracted from juvenile bovine wrists, decellularized, and sized to $4 \mathrm{~mm}$ diameter $\times 5 \mathrm{~mm}$ height. Human BMSCs were expanded and seeded into the decellularized bone cores $\left(2.25 \times 10^{6}\right.$ cells/construct). Seeded constructs were then placed into previously validated perfusion bioreactors ${ }^{21,31}$ and differentiated for 2 weeks in the chondrogenic medium, then matured to hypertrophic chondrocytes over an additional 3 weeks. Flow rates were determined by the tubing diameter, and flow rates approximating $0,100,400$, and $1200 \mu \mathrm{m} / \mathrm{s}$ were chosen for experimentation. At the end of 5 weeks of culture, constructs were implanted into a $5 \mathrm{~mm}$, critical-size defect made in the right femur of RNU nude male rats. Construct regeneration occurred for 8 weeks in vivo before harvest and construct evaluation. BMSC, bone marrow-derived stem cell; RNU, Rowett Nude; SD, standard deviation. Color images available online at www.liebertpub.com/tea 
A

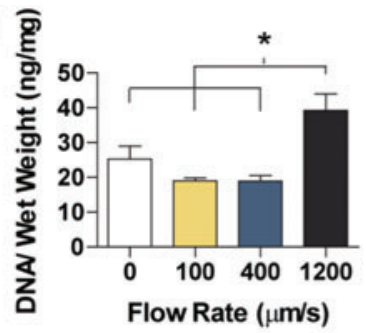

B

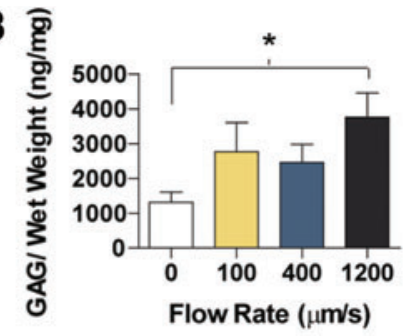

C

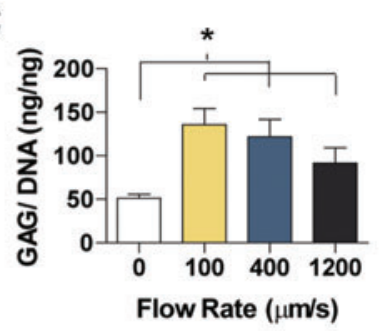

D

Flow Rate

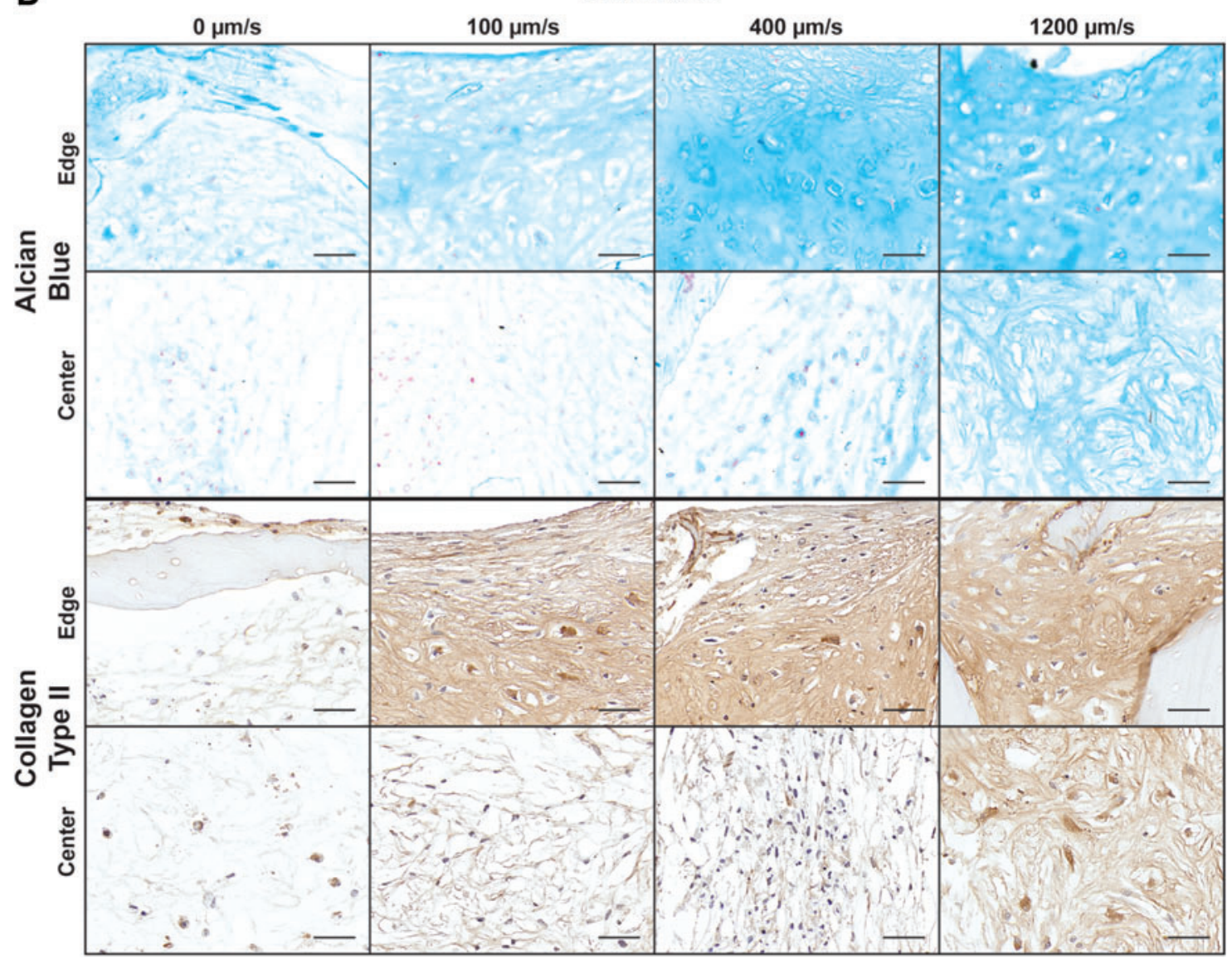

FIG. 2. Chondrogenic differentiation and cartilage matrix production. (A) DNA and (B) GAG content normalized to the tissue wet weight. (C) GAG normalized to DNA contents. (D) Histology and immunohistochemistry evidencing the distribution of GAG (Alcian blue staining) and collagen type II (antibody). Magnified images are shown for the edge and center of the construct. Data are shown as average \pm SD. Asterisk denotes significant differences between the groups, $p<0.05(n=4)$. (D) Scale bars: $50 \mu \mathrm{m}$. GAG, glycosaminoglycan. Color images available online at www.liebertpub.com/tea

$1200 \mu \mathrm{m} / \mathrm{s}$ group, and was significantly higher than in the $0 \mu \mathrm{m} /$ s group (Fig. 2B). To determine matrix production per cell, the GAG content was normalized to the amount of DNA. All three perfusion flow groups $(100,400$, and $1200 \mu \mathrm{m} / \mathrm{s})$ had significantly more GAG/DNA than the control group (Fig. 2C). The histological staining of GAG, by Alcian blue, was consistent with the GAG content (Fig. 2D), and the increased flow rate corresponded to increased Alcian blue staining. Of particular interest was the GAG staining located at the construct centers, as an increased flow rate resulted in increased GAG presence. Collagen type II staining matched Alcian blue, with the $0 \mu \mathrm{m} / \mathrm{s}$ having relatively faint staining for collagen type II with a progression in staining intensity that corresponded with an increased flow rate (Fig. 2D). Consistently, faster flow rates resulted in enhanced staining for cartilaginous matrix within the construct interior.

Collagen type $\mathrm{X}$ is a unique marker for chondrocyte hypertrophy, ${ }^{33}$ and the in vitro chondrogenic differentiation has been associated with cell hypertrophy and collagen type X deposition. ${ }^{34}$ To evaluate the impact of perfusion on chondrocyte hypertrophy, both during chondrogenic differentiation and induced hypertrophic maturation, tissue samples were immunohistochemically stained for collagen type X (Fig. 3). In general, collagen type $\mathrm{X}$ staining for both time points matched the GAG and collagen type II staining, with the faster flow rates corresponding to the higher presence of collagen type $\mathrm{X}$ within the center of the constructs. Interestingly, the localization of the collagen type $\mathrm{X}$ appeared to differ between the two time points. 


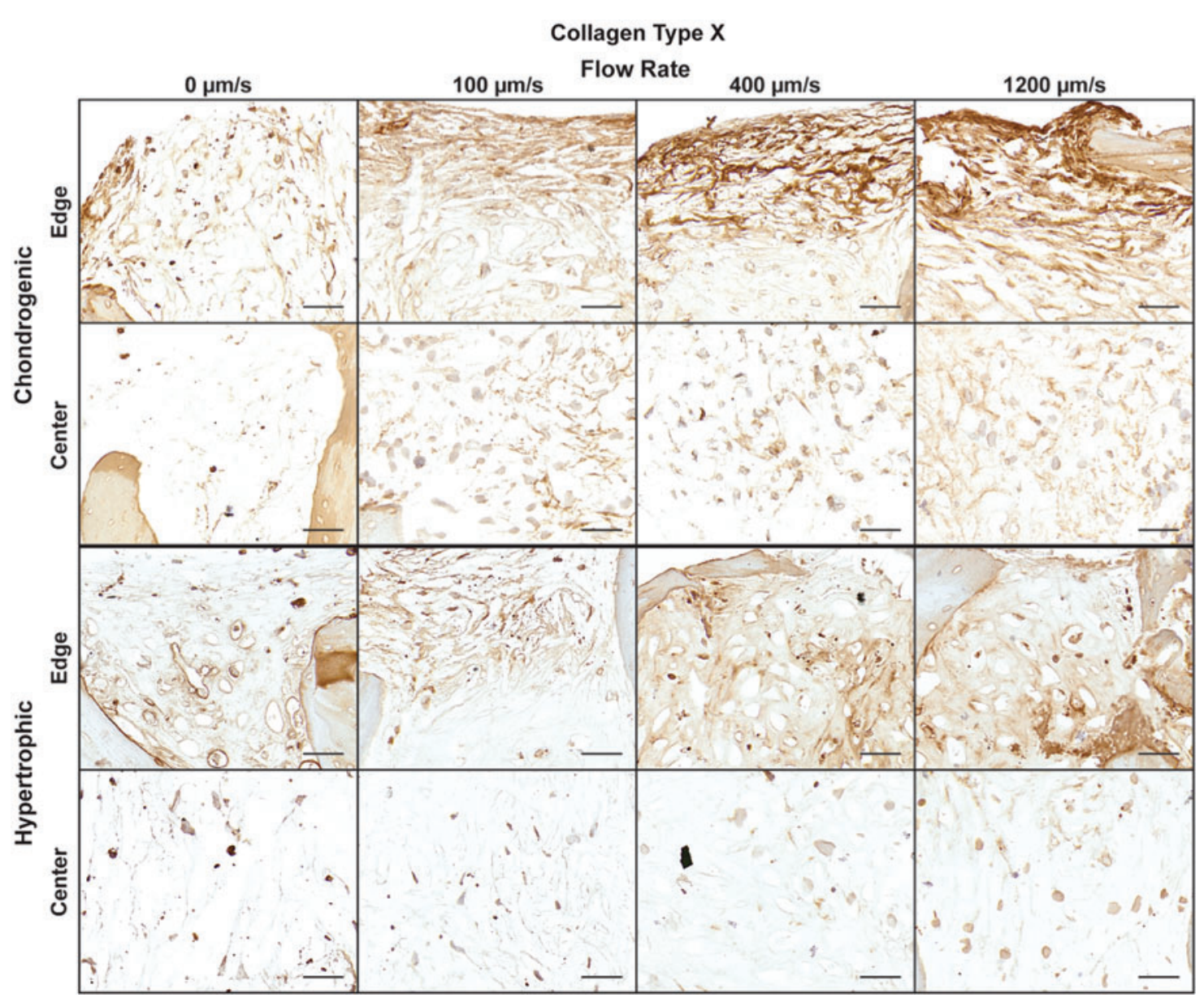

FIG. 3. Hypertrophic chondrocyte maturation. Immunohistochemistry for collagen type $X$ at the end of chondrogenic and hypertrophic culture. Magnified images are shown for both the edge of the construct and the center of the construct. Scale bars: $50 \mu \mathrm{m}$. Color images available online at www.liebertpub.com/tea

During chondrogenic culture, the collagen type $\mathrm{X}$ staining seemed to be only fibrillar, and was dispersed throughout the construct volume; during hypertrophic maturation, pericellular localization of collagen type $\mathrm{X}$ was noticeable in all four groups.

The progression to hypertrophy changed the biochemical characteristics of the constructs (Fig. 4). The DNA content among the four groups was similar, with the $1200 \mu \mathrm{m} / \mathrm{s}$ group having a twofold reduction in DNA content during the 3 weeks of hypertrophic culture (Fig. 4A). As expected with the turnover from a cartilage matrix to a hypertrophic bone template, the GAG content was reduced in all groups, with the maintenance of higher GAG and GAG/DNA contents at higher perfusion flow rates (Fig. 4B). In contrast to the chondrogenic analysis, the hypertrophic GAG/DNA content matched the GAG content trend, with the $1200 \mu \mathrm{m} / \mathrm{s}$ containing significantly more GAG/DNA than the 0 and $100 \mu \mathrm{m} / \mathrm{s}$ groups (Fig. 4C). Despite the differences in matrix content, the expression of advanced hypertrophic chondrocyte and bone production genes did not vary significantly among the groups (Fig. 4D).

Histological and immunochemistry sections of the hypertrophic constructs confirmed the differences in matrix production quantified in Figure 4. Movat's pentachrome staining was utilized to visualize the morphology of the constructs, with cell nuclei in dark red/black, GAG in green, and collagen in yellow (Fig. 5). The reduced flow rates $(0$ and $100 \mu \mathrm{m} / \mathrm{s}$ ) had minimal matrix deposition, with very little GAG and collagen present in both the edge and center sections. The cell morphology in the $0 \mu \mathrm{m} / \mathrm{s}$ group appeared round, while the application of $100 \mu \mathrm{m} / \mathrm{s}$ flow appeared to flatten the cells at the exterior of the construct. Higher flow rates (400 and $1200 \mathrm{~mm} / \mathrm{s}$ ) resulted in clear presence of GAG matching the quantitated data, with GAG surrounding enlarged, rounded chondrocyte lacunae. Unlike any other group, the $1200 \mu \mathrm{m} / \mathrm{s}$ contained both GAG and collagen within the center of the construct. Hypertrophic chondrocytes mediate the turnover of a cartilage matrix to a bone template, ${ }^{35,36}$ with bone sialoprotein (BSP) and osteopontin being important bone matrix proteins secreted by hypertrophic chondrocytes. ${ }^{37,38}$ Similar to GAG deposition, both BSP and osteopontin presence increased with an increased flow rate (Fig. 5). The edges accumulated more matrix with the 400 and $1200 \mu \mathrm{m} / \mathrm{s}$ groups constructing a dense matrix with abundant GAG, BSP, and osteopontin.

With clear differences in matrix deposition during cultivation, the ability of BMSC-derived hypertrophic chondrocyte constructs to facilitate bone regeneration was evaluated in an orthotopic, critical-size femoral defect. For comparison, the static culture group $(0 \mu \mathrm{m} / \mathrm{s})$ and a faster flow rate group $(400 \mu \mathrm{m} / \mathrm{s})$ were implanted for 8 weeks 
A

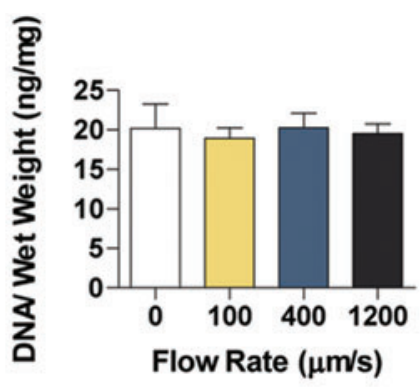

B

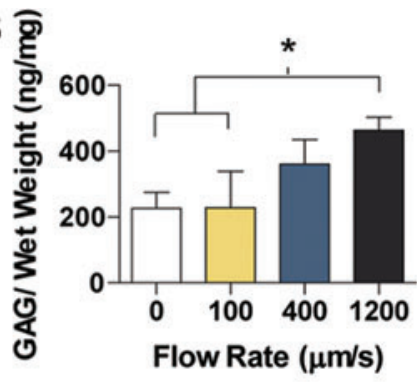

C

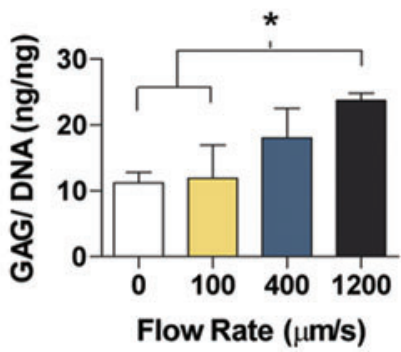

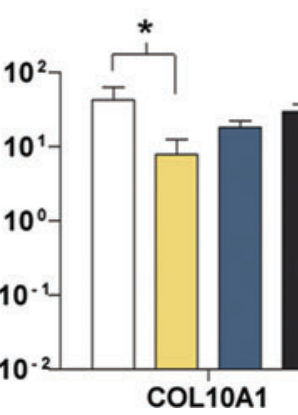
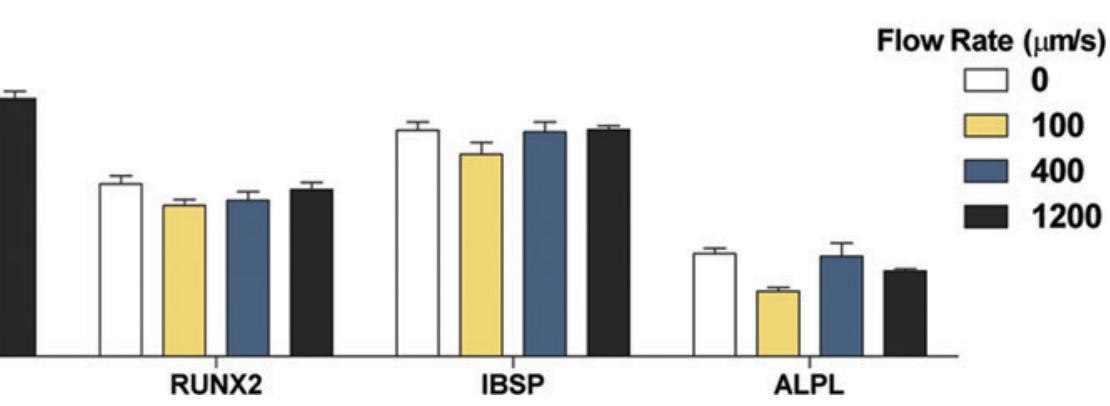

FIG. 4. Biochemical content and gene expression analysis of hypertrophic chondrocyte constructs. (A) DNA per unit wet weight. (B) GAG per unit wet weight. (C) GAG per unit DNA. (D) Expression of key genes related to chondrocyte hypertrophy and bone template formation. Data are shown as average \pm SD. Asterisk denotes significant differences between the groups, $p<0.05(n=4)$. Color images available online at www.liebertpub.com/tea

within the critical-size femoral defect. The two grafts cultured at the faster interstitial flow rates $(400$ and $1200 \mu \mathrm{m} / \mathrm{s})$ were not significantly different in biochemical composition or hypertrophic gene expression (Fig. 4), and contained similar matrix deposition by the differentiated hypertrophic chondrocytes (Figs. 3 and 5). Therefore, we selected the $400 \mu \mathrm{m} / \mathrm{s}$ group for implantation, because of the more frequent and favorable use of this culture condition in previous studies of bone tissue engineering. ${ }^{21,23,30}$ To assess the secreted cytokines at the time of implantation, a series of ELISA tests were conducted on the conditioned medium (Fig. 6A). The concentrations of VEGF, BMP2, and BMP7 were not significantly different between the groups; betacatenin concentration was significantly higher in the $0 \mu \mathrm{m} / \mathrm{s}$ group, while the concentrations of DDK1 and IHH were significantly higher in the $400 \mu \mathrm{m} / \mathrm{s}$ group.

Upon harvest at 8 weeks, tissues were evaluated by highresolution $\mu \mathrm{CT}$ scans $(10 \mu \mathrm{m})$ to obtain $3 \mathrm{D}$ reconstructions and digital images of the graft exterior and interior (Fig. 6B). Bone deposition was evident in both groups, as demonstrated by the smooth, continuous sections seen within the porous trabecular bone. The internal reconstructions demonstrated noticeable differences between the internal bone architectures and the integration with the native femur. In the $0 \mu \mathrm{m} / \mathrm{s}$ group, integration appeared seamless, with only a few areas of incongruity at the proximal interface. In contrast, the $400 \mu \mathrm{m} / \mathrm{s}$ group had noticeable spacing between the femur and the construct at the distal interface. Quantitation of the bone volume in the defect space demonstrated slightly, but not significantly, more bone in the $0 \mu \mathrm{m} / \mathrm{s}$ group (Fig. 6C). Calculation of the BS/BV, an indicator of deposition patterns, showed a significantly lower level for the $0 \mu \mathrm{m} / \mathrm{s}$ group, indicating more compact, voluminous deposition, which matches the groupings seen in the interior $3 \mathrm{D}$ reconstructions.
Tissue samples were then decalcified to investigate differences in bone regeneration (Fig. 7). While neither group displayed complete defect regeneration, bone (yellow) appeared to be more densely deposited at the interface (dashed line) between the native femoral bone and the implanted tissueengineered construct, matching the $\mu \mathrm{CT}$ reconstructions in Figure 6B. Magnified images of the graft-bone interface demonstrated the bone containing empty cellular lacunae, representing the decellularized bone scaffold (white arrows) and cellularized newly formed bone. Over the majority of the interface in the $0 \mu \mathrm{m} / \mathrm{s}$ group, the newly formed bone was in direct contact with the adjacent host bone, whereas fibrous tissue (light red in both the defect and interface images) was present at the interface of the $400 \mu \mathrm{m} / \mathrm{s}$ group.

\section{Discussion}

Hypertrophic chondrocytes derived from human BMSCs represent a promising option for bone tissue engineering. ${ }^{39,40}$ Perfusion bioreactors have demonstrated the ability to enhance the properties of osteochondral constructs, and in this study, our goal was to determine the effect of perfusion flow on hypertrophic chondrocyte differentiation and subsequent bone formation. As demonstrated, an increased perfusion flow facilitated enhanced hypertrophic chondrocyte differentiation and bone matrix deposition in vitro, but this did not correspond to improved bone formation when placed in an orthotopic, critical-sized defect.

As the rate of flow has a major impact on osteoblast differentiation, ${ }^{30}$ flow rates along a broad range were investigated. With the hypertrophic chondrocyte differentiation regime first requiring the derivation of chondrocytes, constructs were harvested after chondrogenic differentiation to evaluate the impact of flow. In agreement with the published literature on perfusion cultures of chondrocytes, increased 


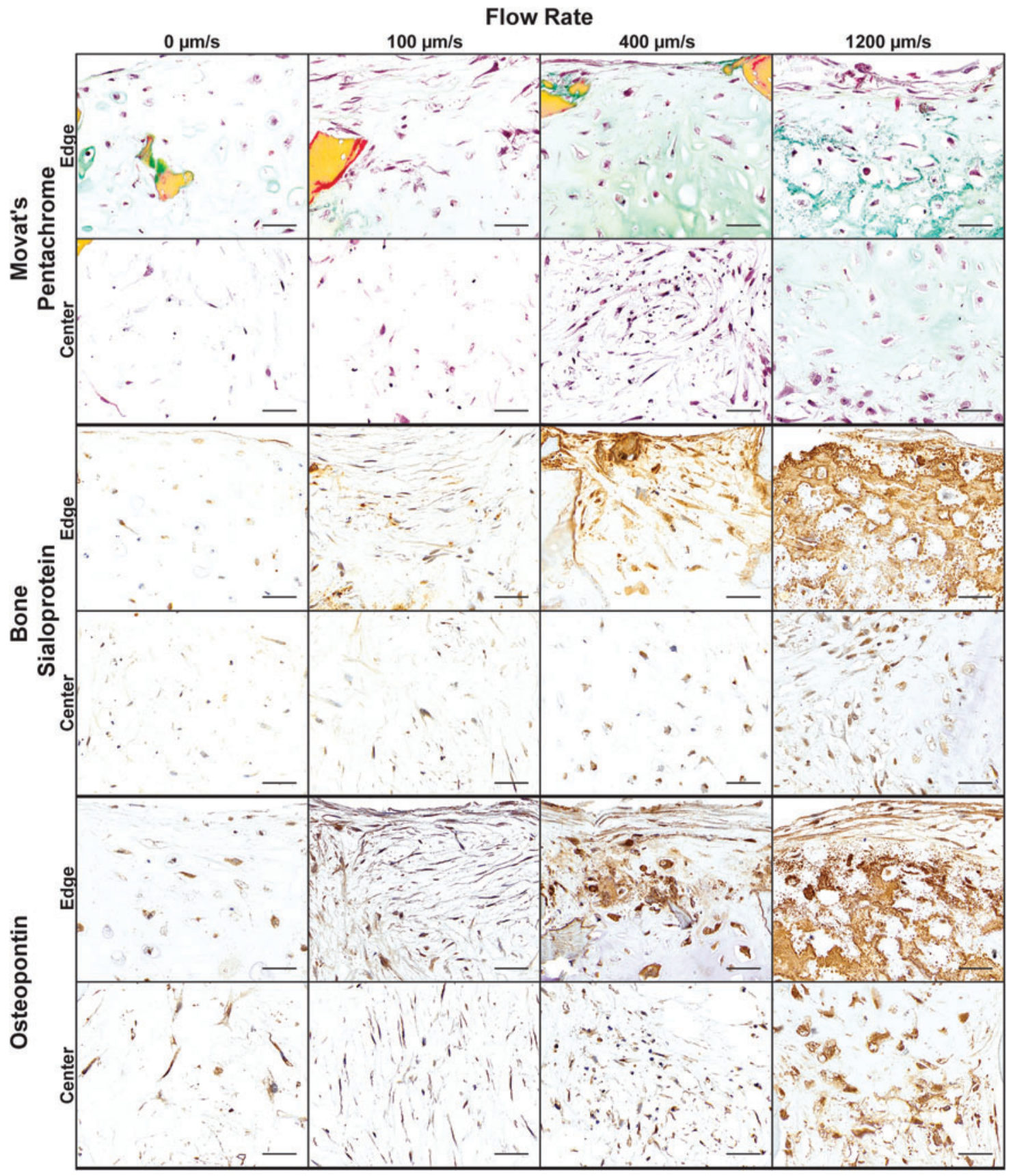

FIG. 5. Construct morphology and bone protein deposition. Histology and immunohistochemistry of constructs for general histomorphology and bone-specific proteins: Movat's pentachrome for GAG (green), collagen (yellow), decellularized scaffold (dark yellow), and cell nuclei (red/black). Immunohistochemistry for BSP and osteopontin. Magnified images are shown for both the edge and center of the construct. Scale bars: $50 \mu \mathrm{m}$. BSP, bone sialoprotein. Color images available online at www.liebertpub.com/tea

flow rates improved chondrocyte differentiation, ${ }^{24-26}$ as shown by the increased GAG deposition per cell (Fig. 2C). The enhanced presence of GAG and collagen type II in the construct interiors at higher flow rates indicated that the improved nutrient delivery dictated this behavior (Fig. 2D). In particular, the ability to deliver TGF- $\beta$ further into the construct volume appeared to promote chondrogenic differentiation and matrix production. ${ }^{41}$

Mathematical modeling of shear stress on chondrocytes suggests that the shear stress had a negative impact on cartilage matrix production, and instead facilitated early hypertrophic maturation. ${ }^{42,43}$ Staining for collagen type X, the unique collagen produced by hypertrophic chondrocytes, was intensified at higher flow rates, indicating an advanced state of maturation (Fig. 3). Despite increased staining, the constructs lacked enlarged lacunae and pericellular collagen type X staining indicative of hypertrophic chondrocytes, ${ }^{38}$ consistent with the existing literature on chondrogenic development of hypertrophy. ${ }^{34,44}$ Cultivation in a hypertrophic differentiation medium promoted the hypertrophic 

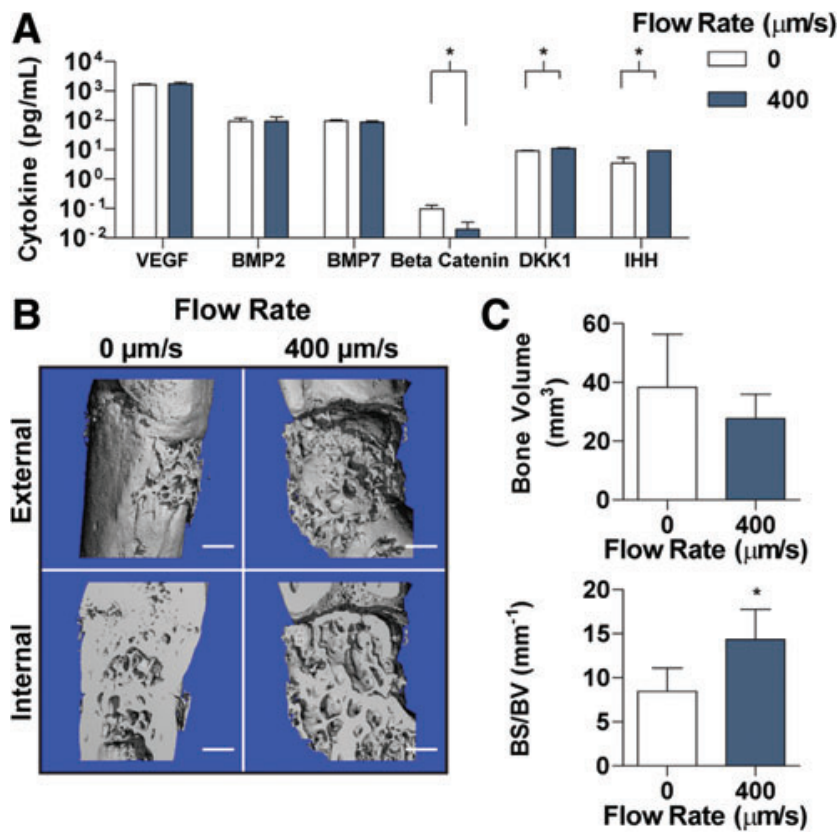

FIG. 6. Construct cytokine release and critical-size defect regeneration. (A) Secreted cytokines into culture medium were detected through ELISA. Cytokines investigated included bone generation cytokines (VEGF, BMP2, BMP7, and beta-catenin) and chondrocyte maintenance cytokines (DKK1 and IHH). (B) $\mu \mathrm{CT}$ of the 0 and $400 \mu \mathrm{m} / \mathrm{s}$ constructs following 8 weeks of implantation in a critical-sized femoral defect in nude rats. (C) The total bone volume and the BS/ $\mathrm{BV}$ were calculated for each group and time point based on the $\mu \mathrm{CT}$ scans. Scale bars: $1 \mathrm{~mm}$. Data are shown as average \pm SD. Asterisk denotes significant differences between the groups, $p<0.05$ (A: $n=6$ constructs run in triplicate, $\mathbf{C}$ : $n=4)$. $\mu \mathrm{CT}$, microcomputed tomography; $\mathrm{BS} / \mathrm{BV}$, bone surface/bone volume. Color images available online at www .liebertpub.com/tea

phenotype, as enlarged chondrocyte lacunae and pericellular collagen type $\mathrm{X}$ became apparent in all groups, with an increased flow rate corresponding to increased collagen type X staining (Fig. 3). Naturally, hypertrophic chondrocyte maturation leads to the remodeling of cartilage matrix and deposition of a bone template. ${ }^{36,45}$ All groups displayed reduction in GAG content; however, the faster flow rates maintained significantly higher amounts of GAG at the end of culture (Fig. 4B, C).

In endochondral ossification, hypertrophic chondrocytes produce a calcified cartilage bone template in which the cartilage GAG influences mineral crystallinity and results in an immature mineral that is the basis of the initial bone. ${ }^{46,47}$ Movat's pentachrome stains supported the biochemical quantitation data, demonstrating that increased flow rates resulted in the increased presence of GAG co-localized with BSP and osteopontin, and indicating the formation of a bone template (Fig. 5). While in the low flow rates the protein staining was present within the cells, the faster flow rates had more advanced bone template deposition with the deposited proteins in a denser pattern, with the extracellular matrix surrounding the enlarged hypertrophic lacunae and resembling hypertrophic cartilage (Fig. 5). ${ }^{46,48}$ The increased perfusion flow rate dictated the deposition patterns

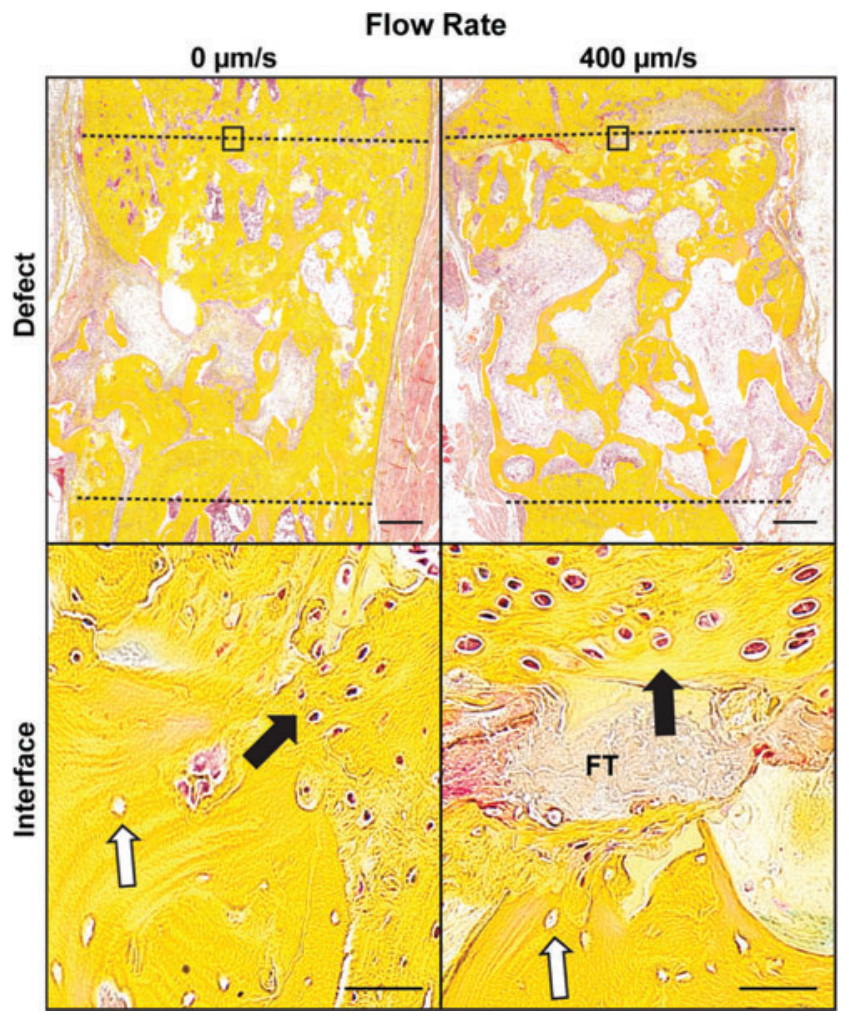

FIG. 7. Histology of critical-size defect regeneration. Movat's pentachrome staining after 8 weeks of 0 and $400 \mu \mathrm{m} / \mathrm{s}$ construct implantation in the critical-size femoral defect. The defect is represented by the dashed lines, where yellow represents bone, and light red represents fibrous tissue. Magnified images of the construct-native bone interface were taken, with the black rectangle indicating the location of the interface within the defect. The white arrows represent the original decellularized bone, indicated by the empty cellular lacunae. Black arrows indicate formed bone, with FT indicating the fibrous tissue that is impeding integration. Scale bars: defect $500 \mu \mathrm{m}$, interface $50 \mu \mathrm{m}$. Color images available online at www.liebertpub.com/tea

of the hypertrophic chondrocytes, consistent with previous studies of osteoblasts and chondrocytes. ${ }^{18,24-26,30}$ Interestingly, the more advanced deposition did not correspond to the expression of key hypertrophic genes (Fig. 4D).

We anticipated that the faster flow rate would result in improved bone regeneration upon implantation, based on the previous osteoblast-based work, which demonstrated that more mature tissue-engineered grafts resulted in enhanced bone regeneration. ${ }^{23}$ However in vivo, the nonperfused $(0 \mu \mathrm{m} / \mathrm{s}$ control) group had more bone deposition and improved integration than the $400 \mu \mathrm{m} / \mathrm{s}$ group (Figs. 6 and 7). As has been shown previously for critical-sized femoral defects in rat, ${ }^{12}$ the bone tissue-engineered grafts regenerate through endochondral ossification, suggesting that the nonperfused grafts may facilitate enhanced endochondral ossification in this study. The progression of in vivo endochondral ossification is thought to be controlled by a number of cytokines, with BMPs, IHH/PTHrP, and Wnt/beta-catenin, providing key pathways to regulate bone formation. ${ }^{49-51}$ In previous studies, cytokines produced by differentiated hypertrophic chondrocytes influenced bone formation and 
remodeling. ${ }^{52}$ In this study, the flow rate did not affect the BMP concentration, indicating that the BMP pathways activated by the tissue-engineered grafts upon implantation did not play a significant role in bone regeneration. IHH is an essential cytokine released by hypertrophic chondrocytes to regulate the production of bone. ${ }^{51}$ Increased levels of IHH have been shown to enhance PTHrP expression, stimulate chondrocyte proliferation, and delay further hypertrophic progression. ${ }^{51,53,54}$ The elevated IHH concentration released by grafts cultured at $400 \mu \mathrm{m} / \mathrm{s}$ suggests higher concentrations of cells in the hypertrophic chondrocyte state. In addition, the cytokines involved in the Wnt/beta-catenin pathway showed significantly different secretion patterns, indicating the different state of each graft (Fig. 6A). DKK1 inhibits hypertrophy by blocking the Wnt pathway, is heavily present in articular cartilage, ${ }^{55}$ and had a significantly higher concentration in the $400 \mu \mathrm{m} / \mathrm{s}$ grafts (Fig. 6A). In addition, betacatenin, responsible for locally mediating osteoblast activity and the turnover of cartilage matrix,${ }^{56}$ had a significantly lower concentration in the $400 \mu \mathrm{m} / \mathrm{s}$ group. The higher presence of DKK1 and lower presence of beta-catenin suggest that the $400 \mu \mathrm{m} / \mathrm{s}$ group was actively signaling to maintain its cartilage matrix, and that this signaling may have inhibited bone formation in the implanted graft.

As shown in Figures 4 and 5, the $400 \mu \mathrm{m} / \mathrm{s}$ group had significantly more bone template and collagen matrix. However, after implantation, the grafts cultured at $400 \mu \mathrm{m} / \mathrm{s}$ were resorbed along the graft/native bone interface and replaced with fibrous tissue, failing to heal the critical-size defects. This was in stark contrast to the grafts cultured without perfusion $(0 \mu \mathrm{m} / \mathrm{s})$, where only minimal deposition occurred in vitro, but extensive in vivo deposition led to integration with the native bone and regeneration of the femoral defects. Consistent with our data, the recent study of hypertrophic constructs by Thompson et al. showed that the grafts with a mineralized, more bone template-like scaffold produced inferior results in a calvarial defect model. ${ }^{11}$ In their study, differing location and organization of host osteoblasts between the scaffolds suggested that bone template-like scaffold and implanted hypertrophic chondrocytes influenced cell infiltration and activity. ${ }^{11}$ Coupled with the cytokine secretion data indicating an advanced graft state at $400 \mu \mathrm{m} /$ $\mathrm{s}$, the presence of fibrous tissue at the integration site suggests that the advanced matrix production during in vitro cultivation (Fig. 5) negatively impacted host cell infiltration and subsequent bone regeneration.

A limitation of our study was the single in vivo time point at 8 weeks. With a more comprehensive animal study, the progression of construct integration and bone regeneration could be modeled with more precision. The contribution of host and implanted cells could also be discerned, to determine the influence of bone template on the regeneration. Better understanding of the differentiated hypertrophic state and how the cytokine secretion influences the various stages of endochondral ossification will be invaluable for optimizing the preparation of tissue constructs for bone repair.

In addition, the in vivo implantation of only two out of four experimental groups may also limit the impact of the study. While the experimental data clearly demonstrate that the perfusion flow during in vitro cultivation limits the regenerative ability of hypertrophic chondrocyte-based bone grafts, in vivo data from all experimental groups would provide further insights into the impact of the degree of perfusion in vitro on the performance of these grafts in vivo. The study of all experimental groups in the orthotopic animal model of bone healing would also help clarify future in vitro studies, and help evaluate the in vitro markers that predict in vivo regeneration.

\section{Conclusion}

We documented the impact of perfusion flow on the hypertrophic chondrocyte differentiation and matrix production in tissue-engineered constructs, in vitro and in a rat model of long bone repair. Similar to differentiated osteoblasts and chondrocytes, ${ }^{18-26}$ we demonstrated that engineering the environment experienced by the cells also impacted hypertrophic chondrocyte differentiation and activity. In particular, the application of shear stress and enhanced nutrient delivery dictated the degree of hypertrophic differentiation and advanced bone template deposition in vitro. The responsive nature of hypertrophic chondrocytes to perfusion flow matched a previous study that showed their sensitivity to specific components in engineered scaffolds ${ }^{11}$ and indicates the ability to engineer an ideal environment for hypertrophic chondrocyte-based bone graft creation. Unlike with osteoblast-based bone grafts, the results of our study suggest that the utilization of perfusion flow for the differentiation and stimulation of hypertrophic chondrocytes may not be appropriate for the construction of clinically relevant tissue-engineered bone grafts.

The positive regeneration facilitated by the control constructs, with a less developed template, but enhanced cell signaling secretion, suggests that enacting an immature, developmental tissue engineering approach, rather than producing tissue-engineered grafts that resemble mature tissue, might be a better route for the future of bone tissue engineering and its application in the clinic. ${ }^{1}$ To educate this opinion, further investigation into the specific activity of the differentiated hypertrophic chondrocytes, when implanted in vivo, is needed.

\section{Acknowledgments}

We gratefully acknowledge the NIH funding support of this work (grants EB002520, DE016525, and AR061988).

\section{Disclosure Statement}

No competing financial interests exist.

\section{References}

1. Lenas, P., Moos, M., and Luyten, F.P. Developmental engineering: a new paradigm for the design and manufacturing of cell-based products. Part I: from three-dimensional cell growth to biomimetics of in vivo development. Tissue Eng Part B Rev 15, 381, 2009.

2. Dennis, S.C., Berkland, C.J., Bonewald, L.F., and Detamore, M.S. Endochondral ossification for enhancing bone regeneration: converging native extracellular matrix biomaterials and developmental engineering in vivo. Tissue Eng Part B Rev 21, 247, 2015.

3. Farrell, E., Both, S.K., Odorfer, K.I., et al. In-vivo generation of bone via endochondral ossification by in-vitro 
chondrogenic priming of adult human and rat mesenchymal stem cells. BMC Musculoskelet Disord 12, 31, 2011.

4. Farrell, E., van der Jagt, O.P., Koevoet, W., et al. Chondrogenic priming of human bone marrow stromal cells: a better route to bone repair? Tissue Eng Part C Methods 15, 285, 2009.

5. Harada, N., Watanabe, Y., Sato, K., et al. Bone regeneration in a massive rat femur defect through endochondral ossification achieved with chondrogenically differentiated MSCs in a degradable scaffold. Biomaterials 35, 7800, 2014.

6. Scotti, C., Piccinini, E., Takizawa, H., et al. Engineering of a functional bone organ through endochondral ossification. Proc Natl Acad Sci U S A 110, 3997, 2013.

7. van der Stok, J., Koolen, M.K., Jahr, H., et al. Chondrogenically differentiated mesenchymal stromal cell pellets stimulate endochondral bone regeneration in criticalsized bone defects. Eur Cell Mater 27, 137, 2014.

8. Scotti, C., Tonnarelli, B., Papadimitropoulos, A., et al. Recapitulation of endochondral bone formation using human adult mesenchymal stem cells as a paradigm for developmental engineering. Proc Natl Acad Sci U S A 107, 7251, 2010.

9. Sheehy, E.J., Mesallati, T., Kelly, L., Vinardell, T., Buckley, C.T., and Kelly, D.J. Tissue engineering whole bones through endochondral ossification: regenerating the distal phalanx. Biores Open Access 4, 229, 2015.

10. Bardsley, K., Kwarciak, A., Freeman, C., Brook, I., Hatton, P., and Crawford, A. Repair of bone defects in vivo using tissue engineered hypertrophic cartilage grafts produced from nasal chondrocytes. Biomaterials 112, 313, 2017.

11. Thompson, E.M., Matsiko, A., Kelly, D.J., Gleeson, J.P., and O'Brien, F.J. An Endochondral ossification-based approach to bone repair: chondrogenically primed mesenchymal stem cell-laden scaffolds support greater repair of critical-sized cranial defects than osteogenically stimulated constructs in vivo. Tissue Eng Part A 22, 556, 2016.

12. Bernhard, J., Ferguson, J., Rieder, B., et al. Tissueengineered hypertrophic chondrocyte grafts enhanced long bone repair. Biomaterials 139, 202, 2017.

13. Martin, I., Wendt, D., and Heberer, M. The role of bioreactors in tissue engineering. Trends Biotechnol 22, 80, 2004.

14. Rauh, J., Milan, F., Gunther, K.P., and Stiehler, M. Bioreactor systems for bone tissue engineering. Tissue Eng Part B Rev 17, 263, 2011.

15. Salehi-Nik, N., Amoabediny, G., Pouran, B., et al. Engineering parameters in bioreactor's design: a critical aspect in tissue engineering. Biomed Res Int 2013, 762132, 2013.

16. Bancroft, G.N., Sikavitsas, V.I., and Mikos, A.G. Design of a flow perfusion bioreactor system for bone tissue-engineering applications. Tissue Eng 9, 549, 2003.

17. Sikavitsas, V.I., Bancroft, G.N., Holtorf, H.L., Jansen, J.A., and Mikos, A.G. Mineralized matrix deposition by marrow stromal osteoblasts in 3D perfusion culture increases with increasing fluid shear forces. Proc Natl Acad Sci U S A 100, 14683, 2003.

18. Bancroft, G.N., Sikavitsast, V.I., van den Dolder, J., et al. Fluid flow increases mineralized matrix deposition in 3D perfusion culture of marrow stromal osteloblasts in a dosedependent manner. Proc Natl Acad Sci U S A 99, 12600, 2002.

19. Cartmell, S.H., Porter, B.D., Garcia, A.J., and Guldberg, R.E. Effects of medium perfusion rate on cell-seeded threedimensional bone constructs in vitro. Tissue Eng 9, 1197, 2003.
20. Wang, Y.C., Uemura, T., Dong, R., Kojima, H., Tanaka, J., and Tateishi, T. Application of perfusion culture system improves in vitro and in vivo osteogenesis of bone marrowderived osteoblastic cells in porous ceramic materials. Tissue Eng 9, 1205, 2003.

21. Grayson, W.L., Bhumiratana, S., Cannizzaro, C., et al. Effects of initial seeding density and fluid perfusion rate on formation of tissue-engineered bone. Tissue Eng Part A 14, 1809, 2008.

22. Grayson, W.L., Frohlich, M., Yeager, K., et al. Engineering anatomically shaped human bone grafts. Proc Natl Acad Sci U S A 107, 3299, 2010.

23. Bhumiratana, S., Bernhard, J.C., Alfi, D.M., et al. Tissueengineered autologous grafts for facial bone reconstruction. Sci Transl Med 8, 343ra83, 2016.

24. Alves da Silva, M.L., Martins, A., Costa-Pinto, A.R., et al. Chondrogenic differentiation of human bone marrow mesenchymal stem cells in chitosan-based scaffolds using a flow-perfusion bioreactor. J Tissue Eng Regen Med 5, 722, 2011.

25. Goncalves, A., Costa, P., Rodrigues, M.T., Dias, I.R., Reis, R.L., and Gomes, M.E. Effect of flow perfusion conditions in the chondrogenic differentiation of bone marrow stromal cells cultured onto starch based biodegradable scaffolds. Acta Biomater 7, 1644, 2011.

26. Mahmoudifar, N., and Doran, P.M. Chondrogenic differentiation of human adipose-derived stem cells in polyglycolic acid mesh scaffolds under dynamic culture conditions. Biomaterials 31, 3858, 2010.

27. Kock, L.M., Malda, J., Dhert, W.J.A., Ito, K., and Gawlitta, D. Flow-perfusion interferes with chondrogenic and hypertrophic matrix production by mesenchymal stem cells. J Biomech 47, 2122, 2014.

28. Nowlan, N.C., Murphy, P., and Prendergast, P.J. A dynamic pattern of mechanical stimulation promotes ossification in avian embryonic long bones. J Biomech 41, 249, 2008.

29. Inoue, H., Arai, Y., Terauchi, R., et al. Effect of mechanical stress on the hypertrophic differentiation related gene expression in cultured chondrocytes. Osteoarthr Cartil 21, S212, 2013.

30. Grayson, W.L., Marolt, D., Bhumiratana, S., Fröhlich, M., Guo, X.E., and Vunjak-Novakovic, G. Optimizing the medium perfusion rate in bone tissue engineering bioreactors. Biotechnol Bioeng 108, 1159, 2011.

31. Frohlich, M., Grayson, W.L., Marolt, D., Gimble, J.M., Kregar-Velikonja, N., and Vunjak-Novakovic, G. Bone grafts engineered from human adipose-derived stem cells in perfusion bioreactor culture. Tissue Eng Part A 16, 179, 2010.

32. Betz, O.B., Betz, V.M., Abdulazim, A., et al. The repair of critical-sized bone defects using expedited, autologous BMP-2 gene-activated fat implants. Tissue Eng Part A 16, 1093, 2010.

33. Vondermark, K., Kirsch, T., Nerlich, A., et al. Type-X collagen-synthesis in human osteoarthritic cartilage-indication of chondrocyte hypertrophy. Arthritis Rheum 35, 806, 1992.

34. Johnstone, B., Hering, T.M., Caplan, A.I., Goldberg, V.M., and Yoo, J.U. In vitro chondrogenesis of bone marrowderived mesenchymal progenitor cells. Exp Cell Res 238, 265, 1998.

35. Bianco, P., Cancedda, F.D., Riminucci, M., and Cancedda, R. Bone formation via cartilage models: the "borderline" chondrocyte. Matrix Biol 17, 185, 1998. 
36. Olsen, B.R., Reginato, A.M., and Wang, W.F. Bone development. Annu Rev Cell Dev Biol 16, 191, 2000.

37. Gerstenfeld, L.C., and Shapiro, F.D. Expression of bonespecific genes by hypertrophic chondrocytes: implications of the complex functions of the hypertrophic chondrocyte during endochondral bone development. J Cell Biochem 62, 1, 1996.

38. Goldring, M.B., Tsuchimochi, K., and Ijiri, K. The control of chondrogenesis. J Cell Biochem 97, 33, 2006.

39. Amini, A.R., Laurencin, C.T., and Nukavarapu, S.P. Bone tissue engineering: recent advances and challenges. Crit Rev Biomed Eng 40, 363, 2012.

40. Thompson, E.M., Matsiko, A., Farrell, E., Kelly, D.J., and O'Brien, F.J. Recapitulating endochondral ossification: a promising route to in vivo bone regeneration. J Tissue Eng Regen Med 9, 889, 2015.

41. Albro, M.B., Nims, R.J., Durney, K.M., et al. Heterogeneous engineered cartilage growth results from gradients of media-supplemented active TGF- $\beta$ and is ameliorated by the alternative supplementation of latent TGF- $\beta$. Biomaterials 77, 173, 2016.

42. Carter, D.R., and Wong, M. Modelling cartilage mechanobiology. Philos Trans R Soc Lond B Biol Sci 358, 1461, 2003.

43. Stevens, S.S., Beaupre, G.S., and Carter, D.R. Computer model of endochondral growth and ossification in long bones: biological and mechanobiological influences. J Orthop Res 17, 646, 1999.

44. Chen, S., Fu, P., Cong, R., Wu, H., and Pei, M. Strategies to minimize hypertrophy in cartilage engineering and regeneration. Genes Dev 2, 76, 2015.

45. Einhorn, T.A. The cell and molecular biology of fracture healing. Clin Orthop Relat Res (355 Suppl), S7, 1998.

46. Duer, M.J., Friščić, T., Murray, R.C., Reid, D.G., and Wise, E.R. The mineral phase of calcified cartilage: its molecular structure and interface with the organic matrix. Biophys $\mathrm{J}$ 96, 3372, 2009.

47. Rey, C., Beshah, K., Griffin, R., and Glimcher, M.J. Structural studies of the mineral phase of calcifying cartilage. J Bone Miner Res 6, 515, 1991.

48. Gerstenfeld, L.C., and Landis, W.J. Gene expression and extracellular matrix ultrastructure of a mineralizing chondrocyte cell culture system. J Cell Biol 112, 501, 1991.
49. Li, J., and Dong, S. The signaling pathways involved in chondrocyte differentiation and hypertrophic differentiation. Stem Cells Int 2016, 12, 2016.

50. Studer, D., Millan, C., Ozturk, E., Maniura-Weber, K., and Zenobi-Wong, M. Molecular and biophysical mechanisms regulating hypertrophic differentiation in chondrocytes and mesenchymal stem cells. Eur Cell Mater 24, 118, 2012.

51. Kozhemyakina, E., Lassar, A.B., and Zelzer, E. A pathway to bone: signaling molecules and transcription factors involved in chondrocyte development and maturation. Development 142, 817, 2015.

52. Bourgine, P.E., Scotti, C., Pigeot, S., Tchang, L.A., Todorov, A., and Martin, I. Osteoinductivity of engineered cartilaginous templates devitalized by inducible apoptosis. Proc Natl Acad Sci U S A 111, 17426, 2014.

53. Vortkamp, A., Lee, K., Lanske, B., Segre, G.V., Kronenberg, H.M., and Tabin, C.J. Regulation of rate of cartilage differentiation by Indian hedgehog and PTH-related protein. Science 273, 613, 1996.

54. Kobayashi, T., Soegiarto, D.W., Yang, Y., et al. Indian hedgehog stimulates periarticular chondrocyte differentiation to regulate growth plate length independently of PTHrP. J Clin Invest 115, 1734, 2005.

55. Leijten, J.C., Emons, J., Sticht, C., et al. Gremlin 1, frizzled-related protein, and Dkk-1 are key regulators of human articular cartilage homeostasis. Arthritis Rheum 64, 3302, 2012.

56. Houben, A., Kostanova-Poliakova, D., Weissenböck, M., et al. $\beta$-catenin activity in late hypertrophic chondrocytes locally orchestrates osteoblastogenesis and osteoclastogenesis. Development 143, 3826, 2016.

Address correspondence to:

Gordana Vunjak-Novakovic, PhD

Department of Biomedical Engineering Columbia University New York, NY 10032

E-mail: gv2131@columbia.edu

Received: August 7, 2017

Accepted: December 19, 2017

Online Publication Date: March 1, 2018 